\title{
microRNA-425-5p is upregulated in human gastric cancer and contributes to invasion and metastasis in vitro and in vivo
}

\author{
ZHUOQI ZHANG ${ }^{1}$, YONG LI ${ }^{1}$, LIQIAO FAN $^{1}$, QUN ZHAO ${ }^{1}$, \\ BIBO TAN ${ }^{1}, \mathrm{ZHONG} \mathrm{LI}^{2}$ and AIMIN ZANG ${ }^{2}$ \\ ${ }^{1}$ Department of General Surgery, The Fourth Affiliated Hospital of Hebei Medical University, Shijiazhuang, Hebei 050011; \\ ${ }^{2}$ Department of Oncological Surgery, Affiliated Hospital of Hebei University, Baoding, Hebei 071000, P.R. China
}

Received July 27, 2014; Accepted February 11, 2015

DOI: $10.3892 /$ etm.2015.2318

\begin{abstract}
Emerging evidence indicates that microRNAs are involved in the development and progression of gastric cancer (GC), functioning as tumor suppressors or oncogenes. The aim of the current study was to explore the potential mechanism of microRNA-425-5p (miR-425-5p) in GC. Using reverse transcription quantitative polymerase chain reaction, miR-425-5p expression was detected in GC cell lines (SGC-7901, MKN-28, MKN-45, BGC-823 and AGS) and the GES-1 cell line. Cell proliferation, soft agar colony formation, flow cytometry, haptotactic migration and matrigel chemoinvasion assays were used to test the proliferation, apoptosis, invasion and migration of BGC-823 cells transfected with miR-425-5p mimics or an inhibitor. Female BALB/c mice were randomly divided into three groups. Each experimental group contained five mice. BGC 823 cells were stably transfected with miR-425-5p inhibitor, wild type or negative control and were injected into the mice through the tail vein. It was found that miR-425-5p expression was significantly upregulated in all the GC cell lines when compared with the GES-1 cell line. Downregulation of miR-425-5p expression inhibited GC cell proliferation, invasion and migration.In the in vivo studies, downregulation of miR-425-5p expression suppressed pulmonary metastasis in the nude mice. Thus, miR-425-5p was demonstrated to have the potential to become a novel metastasis-associated gene; however, the mechanisms associated with these effects require further study. In the future, the development of miR-425-5p as a novel therapeutic strategy for the treatment of GC may be possible.
\end{abstract}

Correspondence to: Dr Yong Li, Department of General Surgery, The Fourth Affiliated Hospital of Hebei Medical University, 12 Jiankang Road, Shijiazhuang, Hebei 050011, P.R. China

E-mail: li_yong_hbth@126.com

Key words: gastric cancer, microRNA-425-5p, invasion, metastasis

\section{Introduction}

Gastric cancer (GC) has the fourth highest incidence rate of human malignant diseases, and causes the second highest number of cancer-related mortalities worldwide (1). Approximately one million new cases are diagnosed each year $(2,3)$, yet early diagnosis of GC in clinical practice remains a challenge. Although gastrectomy remains the mainstay treatment for GC, the prognosis for patients at an advanced stage remains very poor $(4,5)$. With a more complete understanding of the functions of oncogenesis, development and prognosis associated with GC, significant improvements in diagnosis and treatment are possible.

microRNAs (miRNAs) are a category of small, single-stranded endogenous RNA molecules that function as post-transcriptional regulators of gene expression, regulating $>30 \%$ of the protein-coding genes in the human genome (6-8). Increasing evidence indicates that miRNAs are involved in important biological processes associated with apoptosis, proliferation, differentiation, metastasis, angiogenesis and immune responses, the disruption of which may be crucial to cancer initiation, progression and treatment outcomes. miRNA has been demonstrated to be associated with a number of cancer types, including GC, and plays an important role in the disease (9-15).

miRNA-425-5p (miR-425-5p), which is mapped to human chromosome 3 , has been confirmed to have an abnormally high expression in GC (16). In the present study, the expression of miR-425-5p was analyzed in human GC cell lines, and in vitro and in vivo experiments were performed to investigate the associations with local tumor invasion and distant spreading. The aim of the current study was to explore the potential mechanism of miR-425-5p in GC.

\section{Materials and methods}

Cell lines and reagents. Human gastric adenocarcinoma cell lines, SGC-7901, MKN-28, MKN-45 and BGC-823, and a human immortal gastric mucosal epithelial cell line, GES-1, were cultured at the Fourth Affiliated Hospital of Hebei Medical University (Shijiazhuang, China). A human gastric adenocarcinoma cell line, AGS, was obtained from Shanghai Institute of Biochemistry and Cell Biology (Shanghai, 
China). The cell lines, with the exception of the AGS cells, were grown in Dulbecco's modified Eagle's medium (Gibco Life Technologies, Carlsbad, CA, USA) supplemented with $10 \%$ (vol/vol) fetal bovine serum (FBS), $50 \mathrm{U} / \mathrm{ml}$ penicillin and $50 \mu \mathrm{g} / \mathrm{ml}$ streptomycin. The AGS cells were grown in $\mathrm{F}-12 \mathrm{~K}$ medium (Sigma-Aldrich, St. Louis, MO, USA) supplemented with $10 \%$ (vol/vol) FBS, $50 \mathrm{U} / \mathrm{ml}$ penicillin and $50 \mu \mathrm{g} / \mathrm{ml}$ streptomycin. The cell lines were incubated at $37^{\circ} \mathrm{C}$ in a humidified $5 \%$ (vol/vol) $\mathrm{CO}_{2}$ atmosphere. The present study was approved by the Ethics Committee of the Fourth Affiliated Hospital of Hebei Medical University.

Analysis of miRNA expression using TaqMan reverse transcription-quantitative polymerase chain reaction ( $R T-q P C R)$. Total RNA was extracted from the cells using TRIzol ${ }^{\circledR}$ reagent (Invitrogen Life Technologies, Carlsbad, CA, USA), according to the manufacturer's instructions. The expression of mature miRNA was assayed using a TaqMan miRNA assay (Applied Biosystems Life Technologies, Foster City, CA, USA) specific for hsa-miR-425-5p. Briefly, $10 \mathrm{ng}$ total RNA was reverse transcribed to cDNA with specific stem-loop reverse transcription primers (Applied Biosystems Life Technologies). RT-qPCR was performed using an Applied Biosystems 7900 Real-time PCR system and a TaqMan Universal PCR Master Mix (Applied Biosystems Life Technologies). The predesigned TaqMan ${ }^{\circledR}$ MicroRNA assays included the primer sets and TaqMan ${ }^{\circledR}$ probe that were used. The thermal cycling conditions used for PCR were as follows: $95^{\circ} \mathrm{C}$ for $10 \mathrm{~min}$, followed by 40 cycles at $95^{\circ} \mathrm{C}$ for $15 \mathrm{sec}$ and $60^{\circ} \mathrm{C}$ for $60 \mathrm{sec}(17,18)$. Small nuclear U6 single nucleotide RNA (Applied Biosystems Life Technologies) was used as an internal control, and the relative expression was calculated using the comparative threshold cycle method.

Transient transfection and RNA extraction. Oligonucleotides of hsa-miR-425-5p mimics, miR-425-5p inhibitor and a negative control were purchased from Ambion Life Technologies (Carlsbad, CA, USA). Transfection of BGC-823 cells (which were selected due to their moderate expression level of miR-425-5p and superior growth ability comparing with other cell lines) with the oligonucleotides was performed using Lipofectamine ${ }^{\circledR} 2000$ (Invitrogen Life Technologies) at a final concentration of $100 \mathrm{nM}$. Small molecule RNAs ( $\leq 200$ nucleotides) were extracted from the cell lines using a mirVanaTM miRNA kit (Ambion Life Technologies), according to the manufacturer's instructions.

Flow cytometry assay. At 48 h post-transfection with miR-425-5p mimics and the negative control, BGC-823 cells were collected by trypsinization and washed with phosphate-buffered saline (PBS). For cell-cycle analysis, the cells were fixed with $70 \%$ ethanol and stored overnight at $4^{\circ} \mathrm{C}$. On the following day, the fixed cells were washed with PBS, treated with $50 \mu \mathrm{g} / \mathrm{ml}$ RNase A (Sangon Biotech Co., Ltd., Shanghai, China) and stained with $50 \mu \mathrm{g} / \mathrm{ml}$ propidium iodide for $30 \mathrm{~min}$ in the darkness. The stained cells were analyzed using flow cytometry (FACS Calibur $^{\mathrm{TM}}$; Becton Dickinson, Franklin Lakes, NJ, USA).

Cell proliferation assay. At $24 \mathrm{~h}$ post-transfection with miR-425-5p mimics, miR-425-5p inhibitor and the negative control, BGC- 823 cells $\left(3 \times 10^{3}\right.$ cells/well) were seeded into 96 -well plates and incubated at $37^{\circ} \mathrm{C}$ for $24 \mathrm{~h}$. Cell proliferation was assessed by a water-soluble tetrazolium salt (WST) assay using Cell Counting Kit-8 (CCK-8; Dojindo Molecular Technologies, Inc., Kumamoto, Japan). After incubation for $24 \mathrm{~h}, 20 \mu \mathrm{l}$ CCK-8 reagent were added to each well and incubated at $37^{\circ} \mathrm{C}$ for $2 \mathrm{~h}$. Spectrometric absorbance at $450 \mathrm{~nm}$ was measured using a multilabel counter microplate reader (Safire; Tecan Austria GmbH, Grödig, Austria). Experiments were performed in triplicate.

Soft agar colony formation assay. At $24 \mathrm{~h}$ post-transfection, BGC-823 cells were resuspended in $0.5 \%$ soft agar in RPMI 1640 medium (Invitrogen Life Technologies, Gaithersburg, MD, USA) containing 10\% FBS, and layered onto $0.6 \%$ solidified agar in RPMI 1640 medium containing $10 \%$ FBS in six-well plates $\left(1 \times 10^{3}\right.$ cells/well $)$. The plates were incubated for three weeks. Following staining with $0.2 \%$ p-iodonitrotetrazolium violet (Sangon Biotech Co., Ltd.), the colonies containing $\geq 50$ cells were counted.

Haptotactic migration and Matrigel chemoinvasion assays. A Transwell insert (24-well; pore size, $8 \mu \mathrm{m}$; Corning, Inc., Corning, NY, USA) was used to determine the effects of miR-425-5p on GC cell migration and invasion in vitro. Briefly, transfected cells were starved overnight in serum-free medium. A total of $3 \times 10^{4}$ cells in serum-free medium were added to the upper chamber. The lower chamber was filled with $10 \%$ FBS, which functioned as the chemoattractant. The reaction system was incubated for $48 \mathrm{~h}$ for the migration assay and $72 \mathrm{~h}$ for the invasion assay. For the invasion assay, the inserts had been previously coated with extracellular matrix gel (BD Biosciences, Bedford, MA, USA). On completion of the experiments, cells on the upper surface of the membrane were removed and cells on the lower surface were fixed and stained with $0.1 \%$ crystal violet (Sangon Biotech Co., Ltd.). Five visual fields were randomly selected from each insert and counted under a BX51 Olympus light microscope (Olympus Corporation, Tokyo, Japan).

Metastasis assay in vivo. Female BALB/c mice weighing 15-16 g (Shanghai Laboratory Animal Center of China, Shanghai, China) were randomly divided into three groups. BGC-823 cells $\left(1 \times 10^{6}\right.$ cells/mouse) were stably transfected with $\mathrm{miR}-425-5 \mathrm{p}$ inhibitor, wild type or the negative control and were injected into 4-5-week-old female BALB/C nude mice through the tail vein. The mice were housed for six weeks following the injection and were then euthanized by cervical dislocation. The lungs were dissected and examined histologically. Briefly, formalin-fixed, paraffin-embedded tissues were stained with hematoxylin and eosin. Following staining, the tissues were observed under a light microscope and the number of metastases was counted.

Statistical analysis. Results are expressed as the mean \pm standard deviation from three separate experiments. The statistical significance of the data was analyzed using the Student's t-test for independent samples, and statistical analyses were performed using SPSS software (version 15.0; SPSS, Inc., Chicago, IL, USA). A two-tailed value of $\mathrm{P}<0.05$ 


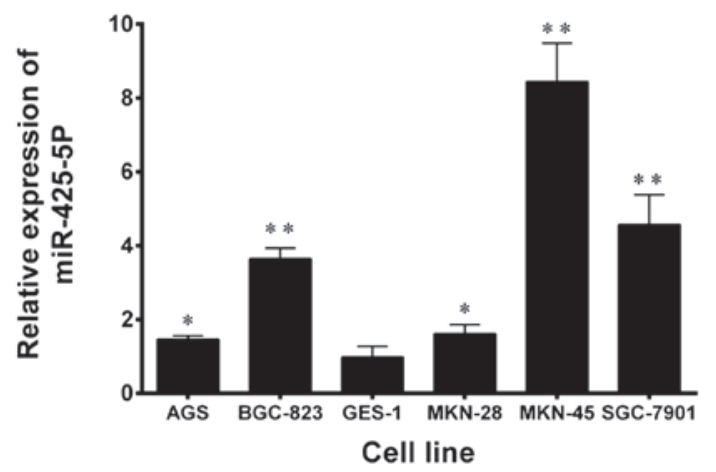

Figure 1. Relative expression levels of miR-425-5p in the five gastric cancer cell lines and the one immortalized normal gastric mucosal epithelial cell line (GES-1) were analyzed using reverse transcription-quantitative polymerase chain reaction. miR, microRNA. ${ }^{*} \mathrm{P}<0.05,{ }^{* *} \mathrm{P}<0.01$ vs. GES- 1 cells.

A

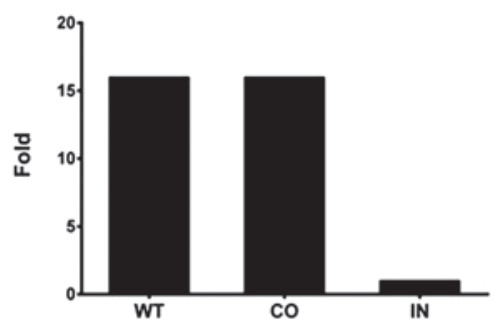

B

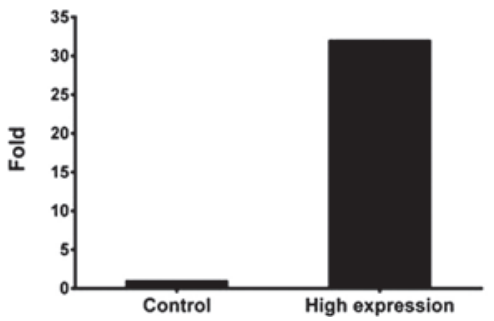

Figure 2. Transfection efficiency of microRNA-425-5p (A) inhibitor and (B) mimics (high expression) in BGC-823 cells. WT, wild type; $\mathrm{CO}$, negative control; IN, inhibitor.

was considered to indicate a statistically significant difference.

\section{Results}

Expression of miR-425-5p is upregulated in GC cell lines. Expression levels of miR-425-5p were evaluated using RT-qPCR in five GC cell lines and a GES-1 cell line. As shown in Fig. 1, miR-425-5p expression was significantly upregulated in all the GC cell lines when compared with the GES-1 cell line. Based on these results and those of a previous study (16), BGC-823 cells were selected for further study.

Assessment of the transient transfection efficiency for miR-425-5p mimics and inhibitor. Transfection efficiency was monitored using RT-qPCR analysis. As shown in Fig. 2, BGC-823 cells transfected with the miR-425-5p inhibitor exhibited significantly lower miR-425-5p expression levels when compared with the wild-type (WT) cells or those transfected with a negative control, while cells transfected with miR-425-5p mimics exhibited significantly higher miRNA expression levels when compared with the negative control cells. In addition, transfection with miR-425-5p mimics did not affect the cell-cycle profile, as demonstrated by flow cytometry (Fig. 3).

Downregulation of miR-425-5p expression inhibits $G C$ cell proliferation. Since miR-425-5p expression was shown to be significantly upregulated in GC tissues and cell lines, the miRNA may function as a tumor promoter. Thus, the effect that low expression levels of miR-425-5p has on cell growth was examined in BGC-823 cells. Synthetic miR-425-5p mimics, miR-425-5p inhibitor and a negative control were transfected into BGC-823 cells, and miR-425-5p expression was confirmed using RT-qPCR analysis.

A WST cell-growth assay revealed significant inhibition of cell growth in the miR-425-5p inhibitor transfectants, as compared with the cells transfected with the negative control and the WT cells $(\mathrm{P}<0.01$; Fig. 4A). Significant promotion of cell growth in the miR-425-5p mimic transfectants was shown, as compared with the control $(\mathrm{P}<0.05$; Fig. $4 \mathrm{~B})$. In order to further characterize the effects of miR-425-5p on cell growth, a colony formation assay was performed in the transfected cells. The number of colonies formed from BGC-823 cells transfected with the miR-425-5p inhibitor was less than half of that formed from the negative control and WT cells $(\mathrm{P}<0.01$; Fig. 4C). BGC-823 cells transfected with the miR-425-5p mimics (high expression) displayed more colonies than the negative control $(\mathrm{P}<0.05$; Fig. 4D). These results demonstrated that miR-425-5p promoted tumorigenicity in GC cells in vitro.

Downregulation of miR-425-5p expression inhibits $G C$ cell invasion and migration. Migration and invasion assays were performed to investigate the mechanisms underlying the effects of miR-425-5p on GC cell migration and invasion. When compared with the control groups, the results demonstrated that downregulation of miR-425-5p expression significantly inhibited the migration and invasion of BGC-823 cells (Fig. 5).

Downregulation of $m i R-425-5 p$ expression suppresses pulmonary metastasis in nude mice. Mice were euthanized six weeks after receiving an injection of transfected cells. The number of lung metastatic nodes per mouse was markedly lower and the nodes were smaller in the mice injected with BGC-823 cells that had been transfected with the miR-425-5p inhibitor, as compared with those in the control and WT groups $(\mathrm{P}<0.05$; Fig. 6).

\section{Discussion}

In recent years, numerous studies have shown that miRNAs may serve as functional 'oncogenes' or 'tumor suppressor genes' by regulating multiple cellular processes associated with tumorigenesis and cancer progression (19-23). Although intensive research effort has been conducted in this area, only a limited number of case studies have identified specific miRNAs that are involved in human tumor formation $(24,25)$. In the current study, miR-425-5p expression was shown to be upregulated in GC cell lines. Furthermore, to the best of our knowledge, the present study demonstrated for the first time 
A
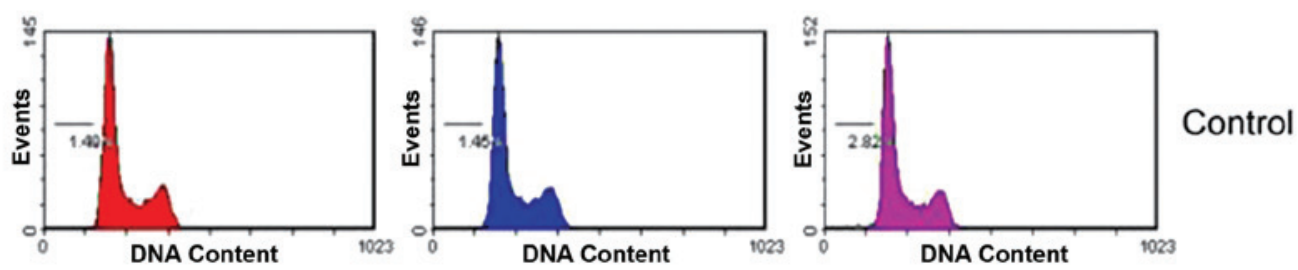

B
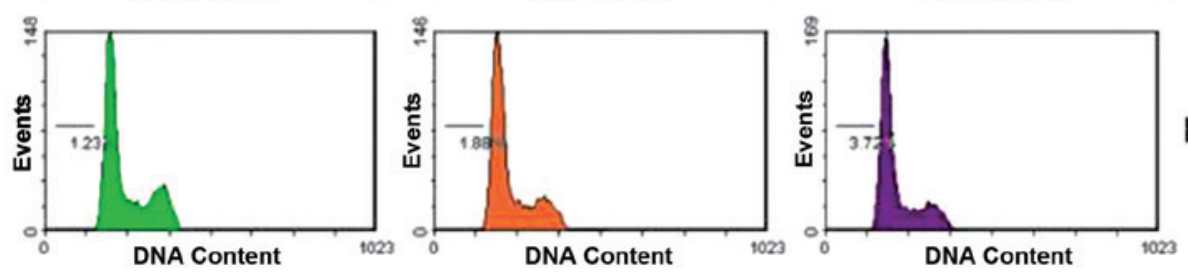

High expression

Figure 3. Flow cytometric analysis of the cells transfected with (A) negative control and (B) microRNA-425-5p mimics. The results reveal that transfection with miR-425-5p mimics did not affect the cell cycle profile.

A

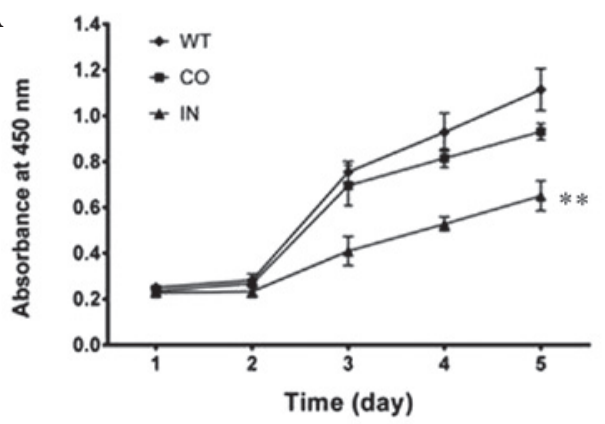

C

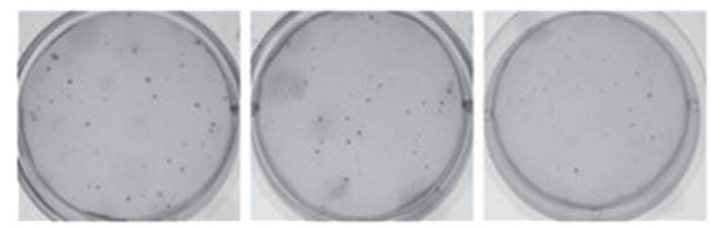

D

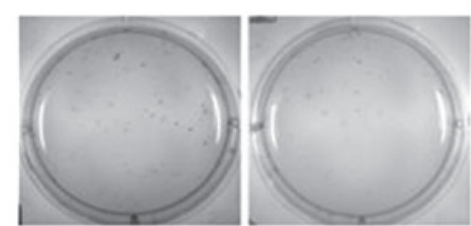

B
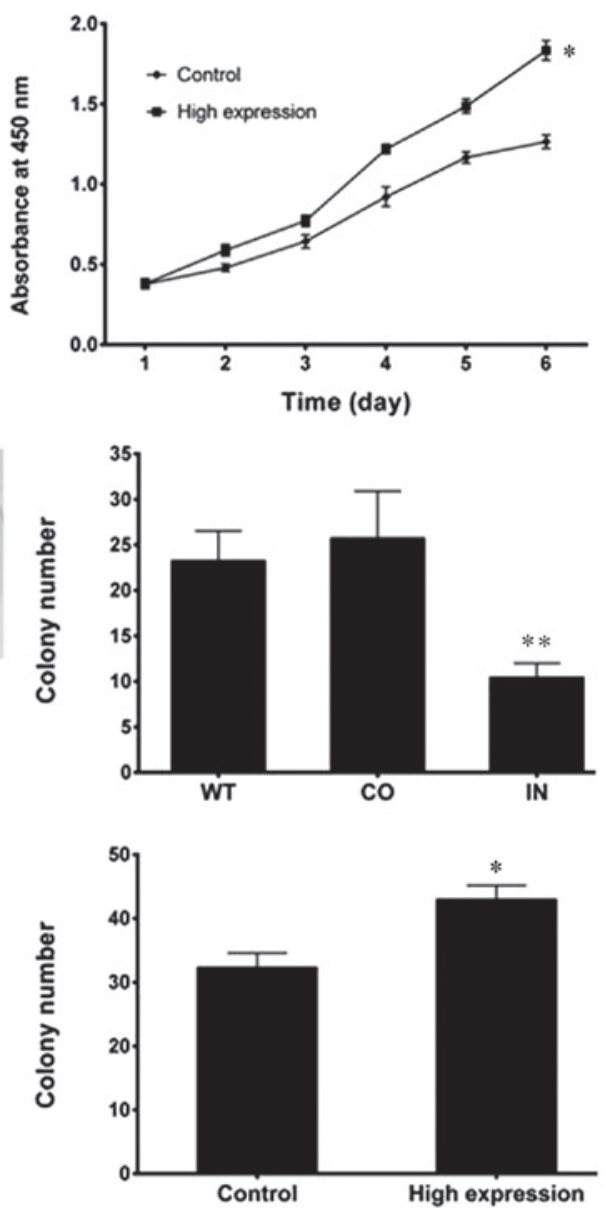

Figure 4. (A) Growth curve of BGC-823 cells following transfection with microRNA-425-5p (miR-425-5p) inhibitor, as compared with CO and WT cells; $\mathrm{P}<0.01$. (B) Growth curve of BGC-823 cells following transfection with miR-425-5p mimics (high expression), as compared with control cells; $\mathrm{P}<0.05$. $(\mathrm{C}$ and $\mathrm{D})$ Colonies containing $\geq 50$ cells were counted; $\mathrm{P}<0.01$. Values are presented as the mean \pm standard deviation from three separate experiments. WT, wild type; $\mathrm{CO}$, negative control; IN, inhibitor.

that miR-425-5p regulates invasion and migration in vitro and in vivo.

In the present study, the results demonstrated that miR-425-5p enhanced GC cell proliferation; however, flow cytometric analysis revealed no effects on the cell cycle and apoptosis. This is inconsistent with the findings of a recently published study (26) that outlined the critical role of nuclear factor- $\kappa \mathrm{B}-$ dependent upregulation of miR-425-5p, which represents a new pathway for the suppression of phosphatase and tensin activation and the promotion of cell survival upon interleukin-1 $\beta$ induction. However, different cell lines and detection methods may cause identical or inconsistent results. 
A

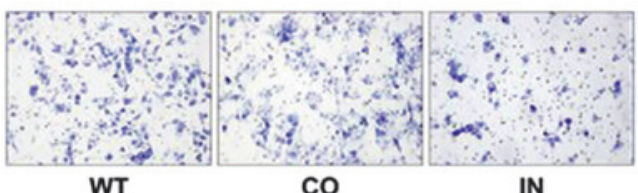

WT
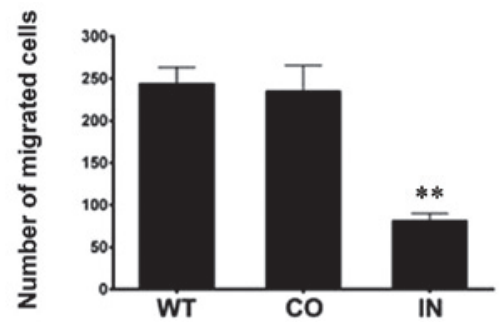

B
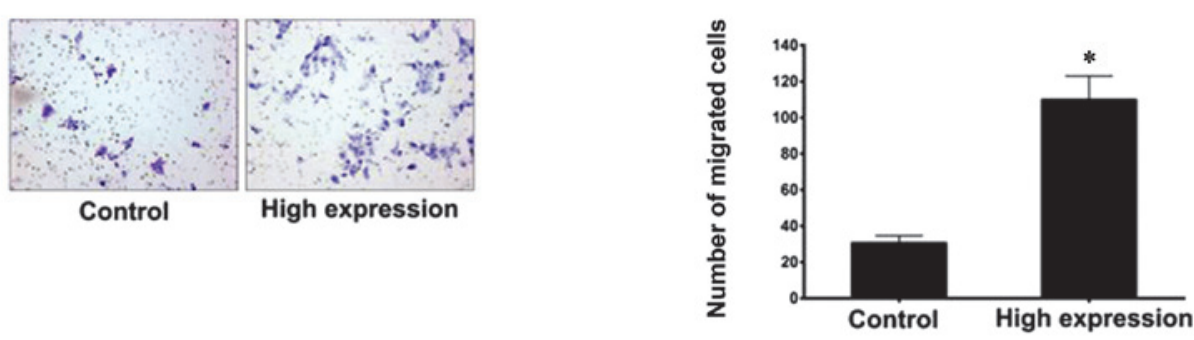

C

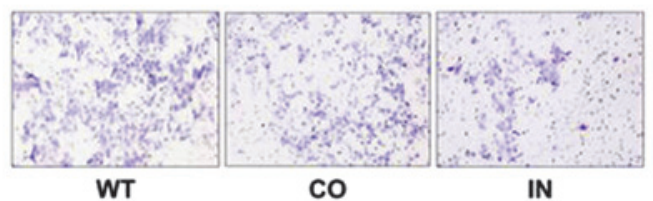

D

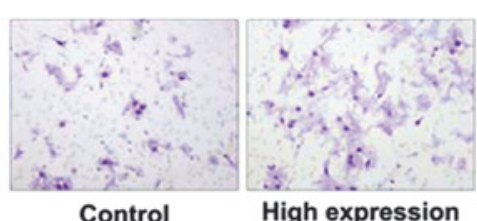

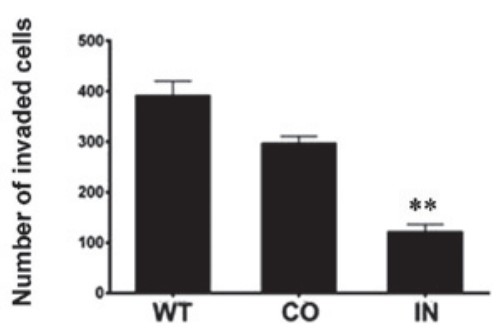

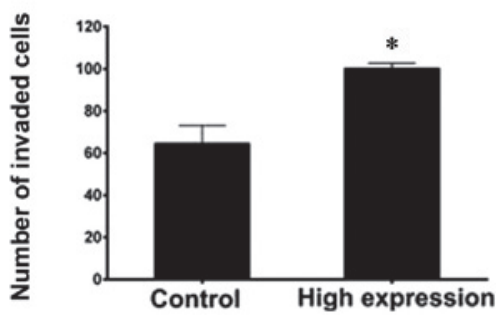

Figure 5. (A) Migration assay of BGC-823 cells following microRNA-425-5p (miR-425-5p) inhibitor transfection, as compared with the CO and WT cells; $\mathrm{P}<0.01$. (B) Migration assay of BGC-823 cells following transfection with miR-425-5p mimics (high expression), as compared with the control cells; $\mathrm{P}<0.05$; (C) Invasion assay of BGC-823 cells following transfection with miR-425-5p inhibitor, as compared with the CO and WT cells; P<0.01. (D) Invasion assay of BGC-823 cells following transfection with miR-425-5p mimics (high expression), as compared with the control cells; $\mathrm{P}<0.05$. IN, inhibitor; CO, negative control; WT, wild type.

A

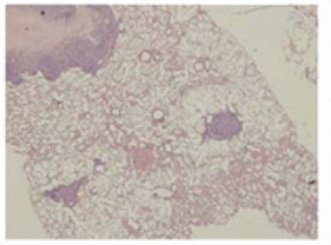

WT

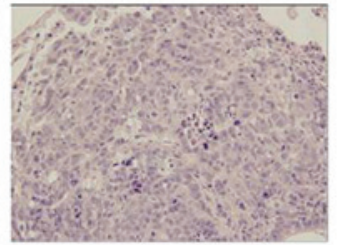

CO

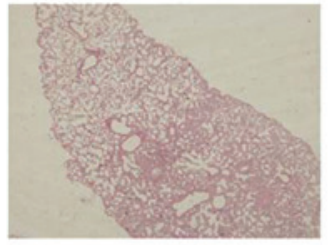

IN

B

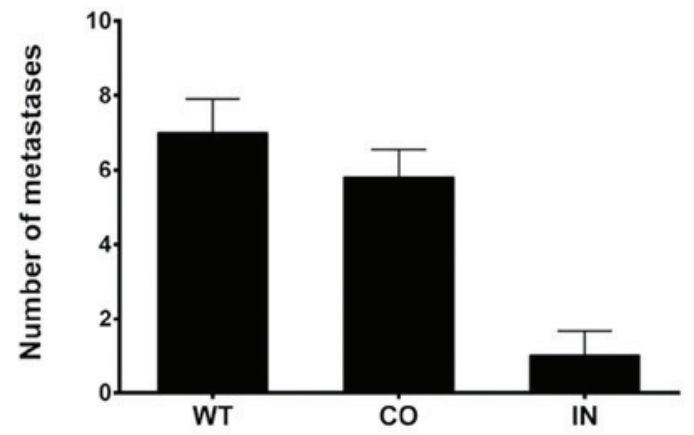

Figure 6. (A) Pathological examination using hematoxylin and eosin staining. (B) Number of tumor metastases. WT, wild type; CO, control, IN, inhibitor. 
Di Leva et al (17) demonstrated a duality in the biological role of miR-191/425 clusters in breast cancer. High levels of estrogen-dependent miR-191/425 were demonstrated to induce proliferation in estrogen receptor- $\alpha$-positive cells by suppressing strong tumor-suppressor genes, such as early growth response protein 1 . However, low levels of miR-191/425 clusters were shown to be essential for the high expression of important modulators, such as special AT-rich sequence binding protein 1, cyclin D2 and fascin actin-bundling protein 1 (FSCN1), which confer a proliferative advantage to aggressive breast cancer cells.

Upon recourse to bioinformatics technology, the target gene of miR-425-5p can be detected. To increase the accuracy of this prediction, genes that were predicted by at least three out of four databases [DIANA LAB (Athens, Greece), Microcosm Targets (Hinxton, UK), TargetScan (Whitehead Institute for Biomedical Research, Cambridge, MA, USA), miRDB (Washington University School of Medicine, St. Louis, MO, USA)] were selected as putative targets. Possible target genes, including SSX2IP, MAP3K5, CLCN4 and FSCN1, and their mechanisms are being further studied by the authors of the present study. In addition, investigation into the existence of two-way adjustment mechanisms and therapeutic targets should be performed in future.

In conclusion, the present study demonstrated that miR-425-5p expression levels are upregulated in GC cell lines. In addition, miR-425-5p was shown to regulate invasion and migration in vitro and in vivo. Therefore, the results indicate that miR-425-5p is an important regulator in the metastasis of GC, demonstrating the potential application of miR-425-5p in GC therapy.

\section{Acknowledgements}

The authors thank Dr Xiaogang Tan for providing technical support in the animal experiments.

\section{References}

1. Jemal A, Bray F, Center MM, Ferlay J, Ward E and Forman D: Global cancer statistics. CA Cancer J Clin 61: 69-90, 2011.

2. Kamangar F, Dores GM and Anderson WF: Patterns of cancer incidence, mortality, and prevalence across five continents: defining priorities to reduce cancer disparities in different geographic regions of the world. J Clin Oncol 24: 2137-2150, 2006.

3. Ferlay J, Shin HR, Bray F, Forman D, Mathers C and Parkin DM: Estimates of worldwide burden of cancer in 2008: GLOBOCAN 2008. Int J Cancer 127: 2893-2917, 2010.

4. Catalano V, Labianca R, Beretta GD, Gatta G, de Braud F and Van Cutsem E: Gastric cancer. Crit Rev Oncol Hematol 71: 127-164, 2009.

5. Parkin DM, Bray F, Ferlay and Pisani P: Global cancer statistics, 2002. CA Cancer J Clin 55: 74-108, 2005.
6. Chen CZ: MicroRNAs as oncogenes and tumor suppressors. N Engl J Med 353: 1768-1771, 2005.

7. Friedman RC, Farh KK, Burge CB and Bartel DP: Most mammalian mRNAs are conserved targets of microRNAs. Genome Res 19: 92-105, 2009.

8. Carthew RW and Sontheimer EJ: Origins and mechanisms of miRNAs and siRNAs. Cell 136: 642-655, 2009.

9. Mirnezami AH, Pickard K, Zhang L, Primrose JN and Packham G: MicroRNAs: key players in carcinogenesis and novel therapeutic targets. Eur J Surg Oncol 35: 339-347, 2009.

10. Ruan K, Fang X and Ouyang G: MicroRNAs: novel regulators in the hallmarks of human cancer. Cancer Lett 285: 116-126, 2009.

11. Kim K, Chadalapaka G, Pathi SS, et al: Induction of the transcriptional repressor ZBTB4 in prostate cancer cells by drug-induced targeting of microRNA-17-92/106b-25 clusters. Mol Cancer Ther 11: 1852-1862, 2012.

12. Selcuklu SD, Donoghue MT, Rehmet K, et al: MicroRNA-9 inhibition of cell proliferation and identification of novel miR-9 targets by transcriptome profiling in breast cancer cells. J Biol Chem 287: 29516-29528, 2012.

13. Dey N, Das F, Ghosh-Choudhury N, et al: microRNA-21 governs TORC1 activation in renal cancer cell proliferation and invasion. PLoS One 7: e37366, 2012.

14. He HC, Zhu JG, Chen XB, et al: MicroRNA-23b downregulates peroxiredoxin III in human prostate cancer. FEBS Lett 586: 2451-2458, 2012.

15. Hur K, Toiyama Y, Takahashi M, et al: MicroRNA-200c modulates epithelial-to-mesenchymal transition (EMT) in human colorectal cancer metastasis. Gut 62: 1315-1326, 2012.

16. Ueda T, Volinia S, Okumura H, et al: Relation between microRNA expression and progression and prognosis of gastric cancer: a microRNA expression analysis. Lancet Oncol 11: 136-146, 2010.

17. Di Leva G, Piovan C, Gasparini P, et al: Estrogen mediated-activation of miR-191/425 cluster modulates tumorigenicity of breast cancer cells depending on estrogen receptor status. PLoS Genet 9: e1003311, 2013.

18. Peng WZ, Ma R, Wang F, Yu J and Liu ZB: Role of miR-191/425 cluster in tumorigenesis and diagnosis of gastric cancer, Int J Mol Sci 15: 4031-4048, 2014.

19. Sander S, Bullinger L, Klapproth K, Fiedler K, et al: MYC stimulates EZH2 expression by repression of its negative regulator miR-26a. Blood 112: 4202-4212, 2008.

20. Jazbutyte V and Thum T: MicroRNA-21: from cancer to cardiovascular disease. Current Drug Targets 11: 926-935, 2010.

21. Uziel T, Karginov FV, Xie S, Parker JS, et al: The miR-17 92 cluster collaborates with the Sonic Hedgehog pathway in medulloblastoma. Proc Natl Acad Sci USA 106: 2812-2817, 2009.

22. Bryant RJ, Pawlowski T, Catto JW, Marsden G, et al: Changes in circulating microRNA levels associated with prostate cancer, $\mathrm{Br}$ J Cancer 106: 768-774, 2012.

23. Wang M, Gu H, Qian H, Zhu W, et al: $\mathrm{miR}-17-5 \mathrm{p} / 20$ a are important markers for gastric cancer and murine double minute 2 participates in their functional regulation. Eur J Cancer 49 2010-2021, 2013.

24. Mavrakis KJ, Wolfe AL, Oricchio E, Palomero T, et al: Genome-wide RNA-mediated interference screen identifies miR-19 targets in Notch-induced T-cell acute lymphoblastic leukaemia. Nat Cell Biol 12: 372-379, 2010.

25. Hsu KW, Wang AM, Ping YH, Huang KH, et al: Downregulation of tumor suppressor MBP-1 by microRNA-363 in gastric carcinogenesis, Carcinogenesis 35: 208-217, 2014.

26. Ma J, Liu J, Wang Z, et al: NF-kappaB-dependent microRNA-425 upregulation promotes gastric cancer cell growth by targeting PTEN upon IL-1beta induction. Mol Cancer 13: 40, 2014. 